\title{
Liraglutide vs Exenatide: Patient Adherence, Medication Persistence and Economic Evaluation in the Treatment of Type 2 Diabetes Mellitus
}

\author{
Fiorenzo Santoleri*, Paola Sorice, Ruggero Lasala, Alberto Costantini \\ Hospital Pharmacy, General Hospital of Pescara, Pescara, Italy \\ Email: fiorenzosantoleri@hotmail.com
}

Received 2 January 2014; revised 9 March 2014; accepted 24 March 2014

Copyright (C) 2014 by authors and Scientific Research Publishing Inc.

This work is licensed under the Creative Commons Attribution International License (CC BY). http://creativecommons.org/licenses/by/4.0/

(c) $\underset{\mathrm{EY}}{\mathrm{B}}$ Open Access

\begin{abstract}
Introduction: Liraglutide and Exenatide are used in adults who are affected by type-2 diabetes to control their blood glucose level. They are administered by the patients by subcutaneous injection, Liraglutide once a day while Exenatide twice a day. The aim of this study was to evaluate medication adherence and persistence of treatment with Liraglutide and Exenatide with a new strategy of calculation also giving economic evaluations on therapy costs for Received Daily Dose. Materials and Methods: In this retrospective study, we took into account 16 months from 1st September 2011 to 31st December 2012. Treatment adherence was quantified utilizing the ratio between RDD and Prescribed Daily Dose (PDD). Persistence is calculated into account the actual therapy days, comparing posology with supplied dose and the graph is drawn using Kaplan-Meir method. Results: The number of patients studied for Liraglutide was 114 and 220 and 58 and 60 for Exenatide respectively in 2011 and 2012. Adherence to therapy, calculated as the ratio between RDD and PDD, in 2011 was 0.93 for Exenatide and 0.87 for Liraglutide, while in 2012 it was 0.94 and 0.90 for Liraglutide and Exenatide, respectively. The cost per day of therapy (cost per RDD) for Liraglutide was $€ 2.88$ and $€ 2.78$ and for Exenatide was $€ 2.37$ and $€ 2.48$ in 2011 and 2012 , respectively. Conclusion: The dosage regimen, therefore, plays an important role in improving the medication adherence.
\end{abstract}

\section{Keywords}

Type-2 Diabetes; Received Daily Dose; Prescribed Daily Dose; Medication Adherence and Persistence

*Corresponding author.

How to cite this paper: Santoleri, F., Sorice, P., Lasala, R. and Costantini, A. (2014) Liraglutide vs Exenatide: Patient Adherence, Medication Persistence and Economic Evaluation in the Treatment of Type 2 Diabetes Mellitus. Pharmacology \& Pharmacy, 5, 332-339. http://dx.doi.org/10.4236/pp.2014.54040 


\section{Introduction}

Diabetes mellitus (DM) is a metabolic disease characterized by hyper glycaemia and reduction in the level or effectiveness of insulin [1]. The number of people affected worldwide by DM was 171 million in 2000 with an estimated rise to 366 million in 2030 with a prevalence of 4.4\% [2]. DM has 2 types, 95\% is type 2 (T2DM). The T2DM is caused mainly by a sedentary life style, obesity, hereditary and other environmental factors [3]. The high prevalence of this disease has had an influence on the health economic system [4]. For this reason, it is very important to study the real management cost of DM. The incretins represent the most recent therapeutic strategy to treat DM. They are capable of preserving and/or regenerating a viable pancreatic beta cell mass [5]. Previously, they were developed to counter postprandial glycaemia, and then they were found to be capable of improving beta cell survival, thus contributing to the long-term, optimal regulation of insulin secretion [6]-[8]. Liraglutide and Exenatide act as glucagon-like peptide-1 (GLP-1) receptors agonists [9]. GLP-1 and glucosedependent insulinotropic polypeptide (GIP) were shown to have a strong insulinotropic activity and they account for as much as 50\% of the insulin released immediately after meal ingestion [10]. GLP-1 inhibits emptying of food from the stomach; thus increases satiety in general and, therefore, decreases food intake. Other therapeutic actions are the improvement of beta cell survival and increase in plasma insulin level [11]. The European Medicines Agency (EMA) authorized the marketing of both Liraglutide and Exenatide in 2010 [12] [13]. Liraglutide and Exenatide stimulate the secretion of insulin, induce the proliferation of pancreatic beta cells and increase the resistance to apoptosis [14] [15]. Liraglutide and Exenatide slow down production of post-prandial plasma glucose in patients suffering from T2DM [16] [17] and they retard gastric emptying [18]. They also induce an increase in glucose-dependent insulin release due to improvement in pancreatic beta cell life annuity via inhibition of apoptosis [19] [20]. All these clinical activities of incretins encourage the use of the treatment of T2DM [21]. Clinically, a 1\% decrease was found in the HAb1c at 12 - 26 weeks for Liraglutide and $0.75 \%$ at 4 - 40 weeks for Exenatide [22]. In addition to their clinical effectiveness, the safety of these drugs was also demonstrated and the necessity to personalize the therapy depended on the patient [23]. Both effectiveness and safety are fundamental parameters for a good adherence, and in fact with a good effectiveness and with no severe adverse reactions, there's no reason to change the therapy. Exenatide's most frequent undesirable effects consist in nausea, vomiting, diarrhea, hypoglycemia; common adverse reaction reported consists of decreased appetite, headache, dyspepsia, abdominal pain, asthenia, weight decreased; reported adverse reactions with the use of Liraglutide are usually anorexia, appetite decreased, headache, nausea, diarrhea, vomiting, dyspepsia; adverse reactions are almost similar for both drugs, then the safety profile probably doesn't affect the difference of adherence between two drugs. The efficacy and safety of Liraglutide and Exenatide have been shown for the treatment of T2DM. Patient adherence remains unstudied [24]. The aim of this study was to investigate medication adherence and persistence to treatment in the patients who used Liraglutide and Exenatide in T2DM for 16 months with a new strategy of calculation, different by the other methods used until now in this kind of study. What we want to emphasize is the originality of the strategy and the new application for these drugs. Pharmacoeconomic analysis has been carried out by calculating the cost per Received Daily Dose (RDD) for each drug.

\section{Materials and Methods}

\subsection{Medication Adherence Figure 1}

T2DM is a chronic disease and so the treatment became "chronic" (long term). In this way, is very important to know the real adherence to treatment. In fact, non-adherence represents a problem both for clinical outcome and loss of economic resources for the health system. In literature several methods are reported to calculate the adherence to treatment such as Continuous Measure of Medication Acquisition (CMA) [25]-[27]; Medication Possession Ratio (MPR) [28]-[30]; Medication Refill Adherence (MRA) [31]-[33]; Proportion of Days Covered (PDC) [34] [35]; Refill Compliance Rate (RCR) [36] [37]; Medication Possession Ratio modified (MPRm) [38]-[40]; Dates Between Fills Adherence Rate (DBR); Compliance Rate (CR); Continuous Multiple Interval Measure of Oversupply (CMOS); Continuous Measure of Medication Gaps (CMG); Continuous, Single Interval Measure of Medication Acquisition (CSA); and Received Daily Dose/Prescribed Daily Dose [41]. The most utilized methods are MPR and PDC [43]. In this study we use the Received Daily Dose/Prescribed Daily Dose method for calculation of Adherence, that we produce and that isn't never used before for antidiabetic drugs. 


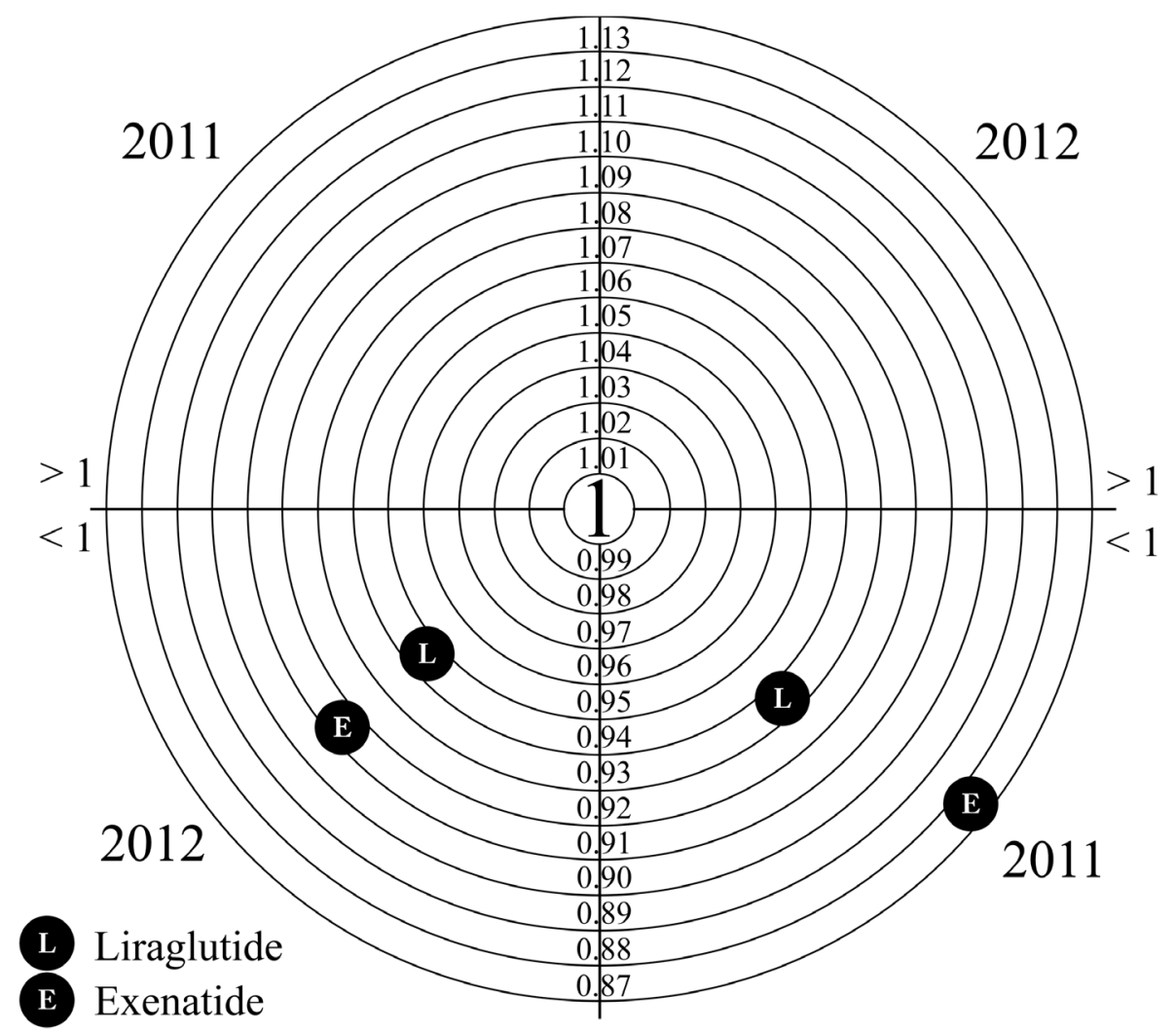

Figure 1. Medication adherence for Liraglutide and Exenatide.

\subsection{Medication Persistence Figure 2}

The medication persistence can be defined as the length of time from initiation to discontinuation of therapy, measured by time in days [43]. Thanks to our understanding of the PDD, we can calculate the real days of treatment computed in relation to the prescribed dose by physician. Medication persistence is an important factor that can be linked to clinical outcome, in fact longer medication persistence can indicate a better clinical profile with less adverse events. On the contrary, therapy is suspended in the case of severe toxicity, pathology progression or death of patient.

This retrospective observational study was carried out from 1st September 2011 to 31st December 2012 in Pescara Hospital Pharmacy (Italy). The study design was approved by the Pescara hospital ethics committee. The written consents were not given by the patients for their information because this is an observational retrospective study as regulated by the Italian Drugs Agency with the "Guidelines for the classification and management of observational studies on drugs", as described in the guidelines available on the website "agenziafarmaco.gov.it". In the case of studies that do not involve a direct relationship with the patient, it is not necessary to administer the privacy consent form to the patient. The analysed data were already in the hospital pharmacy database used daily for clinical practice. All data were analyzed anonymously. Each patient was identified with a personal number. Patients were aware that their data were stored in a specific database, but were not informed that this data were used for research purposes. This procedure has been disclosed to the Ethics Committee who, in accordance with national legislation, approved it. Every patient in therapy with Liraglutide and Exenatide for T2DM was involved in the study. The data of prescription and consumption of incretins were recorded in a database built specifically to follow the patient throughout the care pathway. In this database, called Pharma DDSS, the following data was recorded by the hospital pharmacist: patient demographics, drug used and what it is used for (as prescribed by the physician), Defined Daily Dose (when present) (DDD), Prescribed Daily Dose (PDD) (by physician) and Received Daily Dose (RDD) (by pharmacist). The first three parameters were collected by the hospital pharmacist through consultation with the treatment plan, in which the physician records prescribed drug, dosage, estimated duration of validity of the plan. The hospital pharmacist records all this data in Phar- 


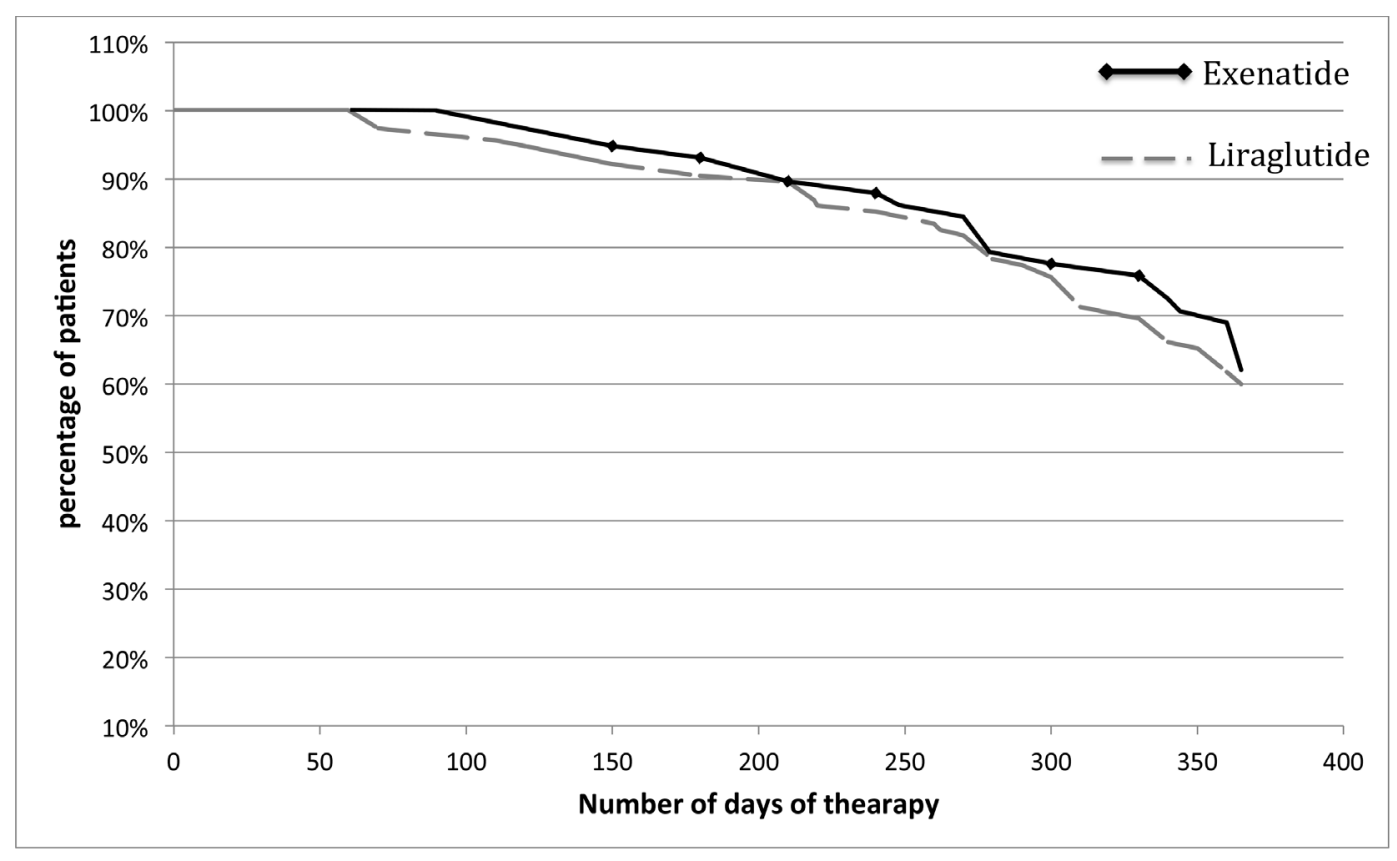

Figure 2. Persistence of treatment for Liraglutide and Exenatide.

ma DDSS. The DDD is the assumed average maintenance dose per day for a drug used for its main indication in adults [44]. Each patient has in his medical record the daily dose as indicated by the physician and the dose of drug received in refill. During the year this dose may be changed by the physician and then updated by the hospital pharmacist. In this way, each patient has a personal record where all doses and change of doses are recorded. The daily dose prescribed is PDD, while RDD is calculated by dividing the dose received by the patient for the number of treatment days. The number of treatment days is considered as the difference between the first and second date of pharmacy refill of drug by the pharmacist in hospital pharmacy. In this way, the hospital pharmacist follows the patient during his health treatment, thus getting to know the medication adherence calculated as the ratio between RDD and PDD. RDD, in fact, can be defined as the dose really taken by the patient and PDD represents the intention to treat. The optimum medication adherence is 1 . The loss of medication adherence is indicated for values less than one. The equation used for the calculation of the adhesion is as follows:

$$
\text { Adherence }=\frac{\text { Received Daily Dose (RDD) }}{\text { Prescribed Daily Dose (RDD) }}
$$

Persistence of therapy was calculated as the total number of days of treatment with the same drug for each patient. We estimate the total days of treatment by adding all the intervals of drug refills and adding also the days covered by the last refill which is obtained by dividing the last dose refilled in the hospital pharmacy by the last prescribed dose.

$$
\text { Days supply with last refill }=\frac{\text { Dose received in last refill }}{\text { PDD }}
$$

For persistence, we consider the effective days in which the patient has taken the drug, thus we deduct from Persistence the NPD (Non Persistence Days) on the basis of Prescribed Dose.

$$
\mathrm{NPD}_{1}=\frac{\text { Dose received in refill }}{1} \text { PDD }- \text { interval }_{1}
$$

Interval $_{1}$ : time in days that elapses between first and second refill.

So the medication persistence is calculated as:

$$
\text { Persistence }=\left(\text { Interval }_{1}-\mathrm{NPD}_{1}\right)+\left(\text { Interval }_{n}-\mathrm{NPD}_{n}\right)+\frac{\text { Dose received in last refill }}{\mathrm{PDD}}
$$




\section{Results}

The number of patients studied was 114 and 220 for Liraglutide and for Exenatide 58 and 60 respectively in 2011 and 2012. The ratio of males to females is similar for both drugs, 49\% and 55\% male for Liraglutide, $43 \%$ and 40\% male for Exenatide, in 2011 and 2012. The median age stood at 58 years for Liraglutide and 63.5 for Exenatide with an age range between 16 years and 82 for Liraglutide and for Exenatide between 37 and 82 (Table 1). The number of patients with T2DM treated with Exenatide was 58 in 2011 and 60 in 2012. However, for the number of patients in 2012 increased significantly for Liraglutide, +92\% compared to 2011. In Table 2 the median days of pharmacological coverage are shown. The weight average of the values of RDD, PDD and Adherence are also shown. In 2011, the analysis was carried out for 4 months (120 days); 94 and 115 days for Exenatide and Liraglutide. In 2012, the median number of exposure days was 210 for Liraglutide and 268 for Exenatide. Adherence to therapy, calculated as the ratio between RDD and PDD, in 2011 was 0.93 for Exenatide and 0.87 for Liraglutide, while in 2012 it was 0.94 and 0.90 for Liraglutide and Exenatide, respectively. The medication persistence is calculated on the basis of actual days of drug coverage in one year and shows the complete overlap of the two curves ( $p<0.05, \chi^{2}=0.126595 \%$ ) describing a similar behaviour of patients who use both drugs in the study. The cost per day of therapy (cost per RDD) for Liraglutide was $€ 2.88$ and $€ 2.78$ and for Exenatide was €2.37 and €2.48 in 2011 and 2012, respectively. From this data one year of treatment with Liraglutide per patient amounted to €1032.95 and €885.12 for Exenatide.

Table 1. Number of patients, sex and age for drug used and year of study.

\begin{tabular}{|c|c|c|c|c|c|c|c|c|}
\hline \multirow{2}{*}{$\begin{array}{l}\text { Drug } \\
\text { Year }\end{array}$} & \multicolumn{4}{|c|}{ Liraglutide } & \multicolumn{4}{|c|}{ Exenatide } \\
\hline & \multicolumn{2}{|c|}{2011} & \multicolumn{2}{|c|}{2012} & \multicolumn{2}{|c|}{2011} & \multicolumn{2}{|c|}{2012} \\
\hline No Patients & \multicolumn{2}{|c|}{114} & \multicolumn{2}{|c|}{220} & \multicolumn{2}{|c|}{58} & \multicolumn{2}{|c|}{60} \\
\hline \multicolumn{9}{|l|}{ Sex } \\
\hline Male & \multicolumn{2}{|c|}{56} & \multicolumn{2}{|c|}{121} & \multicolumn{2}{|c|}{25} & \multicolumn{2}{|c|}{24} \\
\hline Female & \multicolumn{2}{|c|}{58} & \multicolumn{2}{|c|}{99} & \multicolumn{2}{|c|}{33} & \multicolumn{2}{|c|}{36} \\
\hline \multicolumn{9}{|l|}{ Age } \\
\hline Mediane & \multicolumn{2}{|c|}{57.5} & \multicolumn{2}{|c|}{58} & \multicolumn{2}{|c|}{63} & \multicolumn{2}{|c|}{64} \\
\hline Range & 32 & 75 & 16 & 82 & 37 & 81 & 38 & 82 \\
\hline
\end{tabular}

Table 2. Days of treatment, RDD, PDD and adherence for Liraglutide and Exenatide in the years 2011 and 2012.

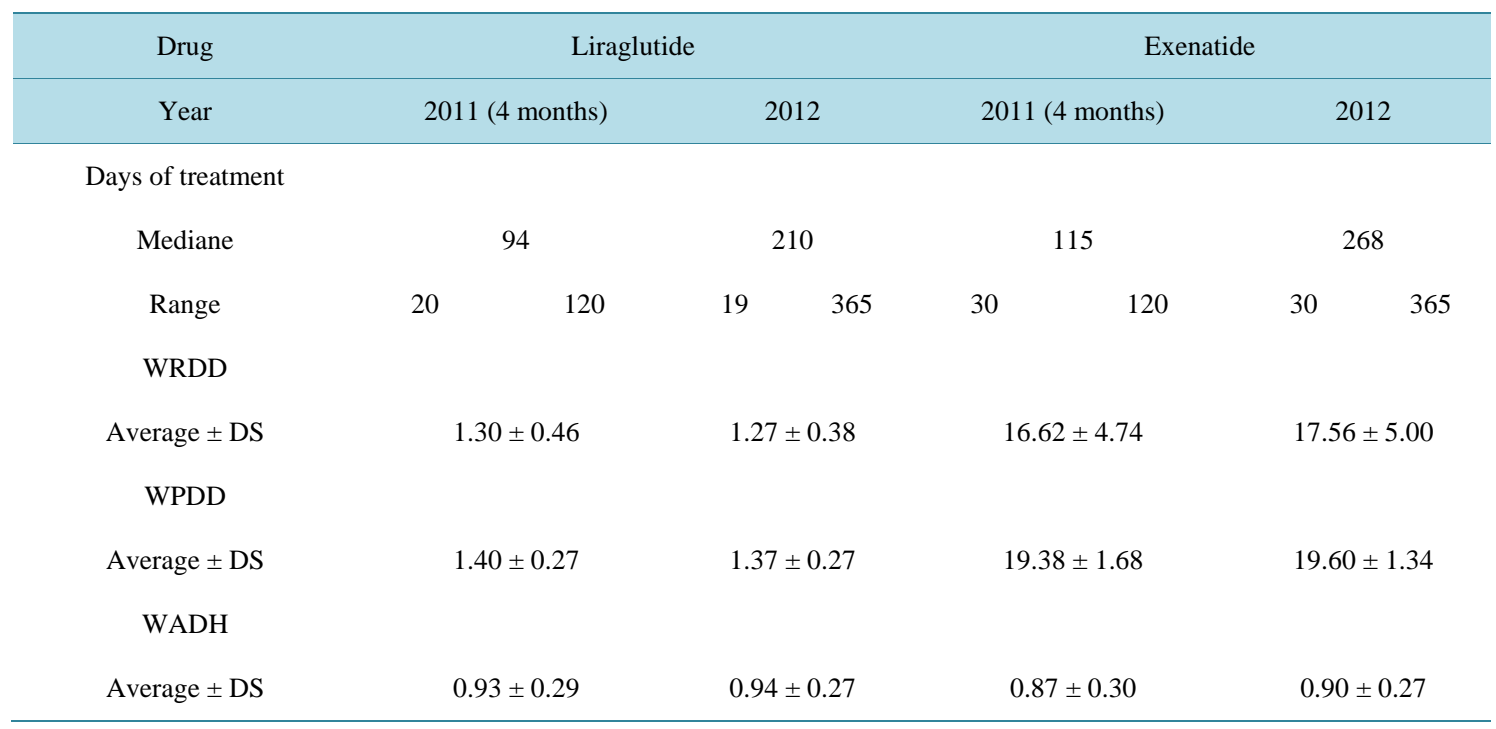




\section{Discussion}

Liraglutide is administered once daily by subcutaneous injection in the abdomen, thigh or upper arm. It can be taken independent of the meal but preferably at the same time of day. The initial dose is $0.6 \mathrm{mg}$ and is then increased to $1.2 \mathrm{mg}$ after the first week of treatment. To improve glycaemic control the daily dose can further increase to $1.8 \mathrm{mg}$ per day. Exenatide, however, should be administered twice a day, starting with 5 mcg in the morning an hour before breakfast and $5 \mathrm{mcg}$ an hour before dinner. The dose may be increased after the first month to $10 \mathrm{mcg}$ twice a day respecting the same dosage schedule. The dosage regimen for Liraglutide tends to be better than the scheme for Exenatide. In the present study, Liraglutide showed a loss of adherence of $7 \%$ and 6\% respectively in 2011 and 2012 while patients who used Exenatide have a loss of adherence of 13\% and 10\%. The difference in medication adherence between the two drugs in study was 47\% in 2011 (7\% vs 13\% Liraglutide/Exenatide) and 40\% in 2012 (6\% vs 10\% Liraglutide/Exenatide). An analysis of the average weight of the prescribed dose (PDD) for Liraglutide in 2011 is equal to $1.40 \mathrm{mg} /$ day and in 2012 was 1.37 mg/day versus 1.2 $\mathrm{mg} /$ day of standard dose per day (DDD). In the same analysis for Exenatide there was a PDD in 2011 that amounted to $19.38 \mathrm{mcg} /$ day and $19.60 \mathrm{mcg} /$ day in 2012 versus the DDD of $15 \mathrm{mcg} / \mathrm{day}$. This finding emphasizes the need to use higher doses than the standard dose to achieve better glycaemic control, in fact the average of Prescribed Daily Dose by clinicians to low the glycaemia is always greater than the Defined Daily Dose in both drugs considered and in both years considered; this factor is important to make a change of direction in the calculation of Adherence, in fact if we consider DDD instead PDD, we have different wrong results, so far by the situation of real pharmacoutilization. For this reason we have made the new strategy based on PDD, that go to brake the actual landscape of strategies adopted for calculation of adherence; in this study we have restricted the objectives focusing on the new strategy, but would be really interesting to correlate to the new concept of adherence with clinical parameters, but that's the next step, for now we think it's useful to introduce the RDD/PDD methodology in the culture of health care professionals and researchers and give them main instruments to calculate with our methodology.

The analysis of persistence to treatment in one year, for both the drugs in the study showed a profile similar. This fact demonstrated further the clinical comparability between Liraglutide and Exenatide in real clinical practice, reflecting a possible comparability in effectiveness and safety profile.

\section{Conclusion}

In the treatment of Type 2 diabetes, the use of agonists of the GLP-1 is continuously growing. However, it's necessary to describe not only the clinical efficacy but also the ability to follow the long-term therapy. In the case of the study drugs, there was a different profile of adherence, better for Liraglutide than Exenatide. In this sense, the mode of administration, less restrictive for the Liraglutide, promotes adherence to treatment. The dosage regimen, therefore, plays an important role in improving the medication adherence. This study of adherence, persistence and costs would be useful to make decisions in healthcare, in fact, with no proof of major effectiveness of one of the two drugs (there isn't a direct comparison between these two drugs in scientific literature), and a better profile in these parameters could be linked to a preference in clinical prescription and use. Liraglutide has a better adherence profile and the persistence to treatment is similar for the drugs, and at the same time Exenatide has a lower cost per RDD than Liraglutide; so, the question we ask is: can a better adherence profile justify a higher cost of treatment? Only deep studies with a greater population and with clinic outcomes in real clinical practice could give an answer.

\section{References}

[1] Maraschin, J. de F. (2012) Classification of Diabetes. Advances in Experimental Medicine and Biology, 771, 12-19.

[2] Wild, S., Roglic, G., Green, A., Sicree, R., et al. (2004) Global Prevalence of Diabetes: Estimates for the Year 2000 and Projections for 2030. Diabetes Care, 27, 1047-1053. http://dx.doi.org/10.2337/diacare.27.5.1047

[3] D’Souza, A., Hussain, M., Howarth, F.C., et al. (2009) Pathogenesis and Pathophysiology of Accelerated Atherosclerosis in the Diabetic Heart. Molecular and Cellular Biochemistry, 331, 89-116. http://dx.doi.org/10.1007/s11010-009-0148-8

[4] Davies, M.J., Chubb, B.D., Smith, I.C., et al. (2012) Cost-Utility Analysis of Liraglutide Compared with Sulphonylurea or Sitagliptin, All as Add-On to Metformin Monotherapy in Type 2 Diabetes Mellitus. Diabetic Medicine, 29, 313320. http://dx.doi.org/10.1111/j.1464-5491.2011.03429.x 
[5] Butler, A.E., Janson, J., Bonner-Weir, S., et al. (2003) Beta-Cell Deficit and Increased Beta-Cell Apoptosis in Humans with Type 2 Diabetes. Diabetes, 52, 102-110. http://dx.doi.org/10.2337/diabetes.52.1.102

[6] Karaca, M., Magnan, C. and Kargar, C. (2009) Functional Pancreatic Beta-Cell Mass: Involvement in Type 2 Diabetes and Therapeutic Intervention. Diabetes \& Metabolism, 35, 77-84. http://dx.doi.org/10.1016/j.diabet.2008.09.007

[7] Creutzfeldt, W. and Ebert, R. (1985) New Developments in the Incretin Concept. Diabetologia, 28, 565-573. http://dx.doi.org/10.1007/BF00281990

[8] Kim, M.H. and Lee, M.K. (2010) The Incretins and Pancreatic beta-Cells: Use of Glucagon-Like Peptide-1 and Glucose-Dependent Insulinotropic Polypeptide to Cure Type 2 Diabetes Mellitus. Korean Diabetes Journal, 34, 2-9. http://dx.doi.org/10.4093/kdj.2010.34.1.2

[9] Baggio, L.L. and Drucker, D.J. (2007) Biology of Incretins: GLP-1 and GIP. Gastroenterology, 132, 2131-2157. http://dx.doi.org/10.1053/j.gastro.2007.03.054

[10] Wideman, R.D. and Kieffer, T.J. (2004) Glucose-Dependent Insulinotropic Polypeptide as a Regulator of Beta Cell Function and Fate. Hormone and Metabolic Research, 36, 782-786. http://dx.doi.org/10.1055/s-2004-826164

[11] Kieffer, T.J. and Habener, J.F. (1999) The Glucagon-Like Peptides. Endocrine Reviews, 20, 876-913. http://dx.doi.org/10.1210/edrv.20.6.0385

[12] European Medicines Agency (2010) Novo Nordisk Summary of Product Characteristics: Victoza ${ }^{\mathrm{TM}}$.

[13] European Medicines Agency (2010) Eli Lilly \& Co Summary of Product Characteristics: Byetta ${ }^{\mathrm{TM}}$.

[14] Aston-Mourney, K., Hull, R.L., Zraika, S., et al. (2011) Exendin-4 Increases Islet Amyloid Deposition but Offsets the Resultant Beta-Cell Toxicity in Human Islet Amyloid Polypeptide Transgenic Mouse Islets. Diabetologia, 54, 17561765. http://dx.doi.org/10.1007/s00125-011-2143-3

[15] Fan, R., Kang, Z., He, L., et al. (2011) Exendin-4 Improves Blood Glucose Control in Both Young and Aging Normal Non-Diabetic Mice, Possible Contribution of Beta Cell Independent Effects. PLoS One, 6, e20443. http://dx.doi.org/10.1371/journal.pone.0020443

[16] Degn, K.B., Juhl, C.B., Sturis, J., et al. (2004) One Week’s Treatment with the Long-Acting Glucagon-Like Peptide 1 Derivative Liraglutide (NN2211) Markedly Improves 24-h Glycemia and Alpha- and Beta-Cell Function and Reduces Endogenous Glucose Release in Patients with Type 2 Diabetes. Diabetes, 53, 1187-1194. http://dx.doi.org/10.2337/diabetes.53.5.1187

[17] Iltz, J.L., Baker, D.E., Setter, S.M., et al. (2006) Exenatide: An Incretin Mimetic for the Treatment of Type 2 Diabetes Mellitus. Clinical Therapeutics, 28, 652-665. http://dx.doi.org/10.1016/i.clinthera.2006.05.006

[18] Juhl, C.B., Hollingdal, M., Sturis, J., et al. (2002) Bedtime Administration of NN2211, a Long-Acting GLP-1 Derivative, Substantially Reduces Fasting and Postprandial Glycemia in Type 2 Diabetes. Diabetes, 51, 424-429. http://dx.doi.org/10.2337/diabetes.51.2.424

[19] Bregenholt, S., Møldrup, A., Blume, N., et al. (2005) The Long-Acting Glucagon-Like Peptide-1 Analogue, Liraglutide, Inhibits Beta-Cell Apoptosis in Vitro. Biochemical and Biophysical Research Communications, 330, 577-584. http://dx.doi.org/10.1016/j.bbrc.2005.03.013

[20] Wajchenberg, B.L. (2007) Beta-Cell Failure in Diabetes and Preservation by Clinical Treatment. Endocrine Reviews, 28, 187-218. http://dx.doi.org/10.1210/10.1210/er.2006-0038

[21] Lotfy, M., Singh, J., Kalász, H., et al. (2011) Medicinal Chemistry and Applications of Incretins and DPP-4 Inhibitors in the Treatment of Type 2 Diabetes Mellitus. The Open Medicinal Chemistry Journal, 5, 82-92. http://dx.doi.org/10.2174/1874104501105010082

[22] Fakhoury, W.K., Lereun, C. and Wright, D. (2010) A Meta-Analysis of Placebo-Controlled Clinical Trials Assessing the Efficacy and Safety of Incretin-Based Medications in Patients with Type 2 Diabetes. Pharmacology, 86, 44-57. http://dx.doi.org/10.1159/000314690

[23] Brown, D.X. and Evans, M. (2012) Choosing between GLP-1 Receptor Agonists and DPP-4 Inhibitors: A Pharmacological Perspective. Journal of Nutrition and Metabolism, 2012, 381713. http://dx.doi.org/10.1155/2012/381713

[24] Doggrell, S.A. (2013) Exenatide Extended-Release; Clinical Trials, Patient Preference, and Economic Considerations. Patient Preference and Adherence, 7, 35-45. http://dx.doi.org/10.2147/PPA.S30627

[25] Karve, S., Cleves, M.A., Helm, M., et al. (2009) Prospective Validation of Eight Different Adherence Measures for Use with Administrative Claims Data among Patients with Schizophrenia. Value in Health, 12, 989-995. http://dx.doi.org/10.1111/j.1524-4733.2009.00543.x

[26] Karve, S., Cleves, M.A., Helm, M., et al. (2008) An Empirical Basis for Standardizing Adherence Measures Derived from Administrative Claims Data among Diabetic Patients. Medical Care, 46, 1125-1133. http://dx.doi.org/10.1097/MLR.0b013e31817924d2

[27] Colombo, G.L., Rossi, E., De Rosa, M., et al. (2012) Antidiabetic Therapy in Real Practice: Indicators for Adherence 
and Treatment Cost. Patient Preference and Adherence, 6, 653-661. http://dx.doi.org/10.2147/ppa.s33968

[28] Dupclay, L., Eaddy, M., Jackson, J., et al. (2012) Real-World Impact of Reminder Packaging on Antihypertensive Treatment Adherence and Persistence. Patient Preference and Adherence, 6, 499-507.

[29] Egede, L.E., Gebregziabher, M., Dismuke, C.E., et al. (2012) Medication Nonadherence in Diabetes: Longitudinal Effects on Costs and Potential Cost Savings from Improvement. Diabetes Care, 35, 2533-2539. http://dx.doi.org/10.2337/dc12-0572

[30] Vollmer, W.M., Feldstein, A., Smith, D.H., et al. (2011) Use of Health Information Technology to Improve Medication Adherence. American Journal of Managed Care, 17, SP79-S87.

[31] Ratanawongsa, N., Karter, A.J., Parker, M.M., et al. (2013) Communication and Medication Refill Adherence: The Diabetes Study of Northern California. JAMA Internal Medicine, 173, 210-218. http://dx.doi.org/10.1001/jamainternmed.2013.1216

[32] Kocarnik, B.M., Liu, C.F., Wong, E.S., et al. (2012) Does the Presence of a Pharmacist in Primary Care Clinics Improve Diabetes Medication Adherence? BMC Health Services Research, 12, 391. http://dx.doi.org/10.1186/1472-6963-12-391

[33] Cocohoba, J.M., Murphy, P., Pietrandoni, G., et al. (2003) Improved Antiretroviral Refill Adherence in HIV-Focused Community Pharmacies. Journal of American Pharmacists Association, 52, e67-e73.

[34] Sharma, K.P. and Taylor, T.N. (2012) Pharmacy Effect on Adherence to Antidiabetic Medications. Medical Care, 50, 685-691. http://dx.doi.org/10.1097/MLR.0b013e318249d800

[35] Yeaw, J., Benner, J.S., Walt, J.G., et al. (2009) Comparing Adherence and Persistence across 6 Chronic Medication Classes. Journal of Managed Care Pharmacy, 15, 728-740.

[36] van den Boogaard, J., Lyimo, R.A., Boeree, M.J., et al. (2011) Electronic Monitoring of Treatment Adherence and Validation of Alternative Adherence Measures in Tuberculosis Patients: A Pilot Study. Bulletin of the World Health Organization, 89, 632-639. http://dx.doi.org/10.2471/BLT.11.086462

[37] Gu, Q., Zeng, F., Patel, B.V., et al. (2010) Part D Coverage Gap and Adherence to Diabetes Medications. American Journal of Managed Care, 16, 911-918.

[38] Egede, L.E., Gebregziabher, M., Hunt, K.J., et al. (2011) Regional, Geographic, and Ethnic Differences in Medication Adherence among Adults with Type 2 Diabetes. The Annals of Pharmacotherapy, 45, 169-178. http://dx.doi.org/10.1345/aph.1P442

[39] Friedman, D.S., Quigley, H.A., Gelb, L., et al. (2007) Using Pharmacy Claims Data to Study Adherence to Glaucoma Medications: Methodology and Findings of the Glaucoma Adherence and Persistency Study (GAPS). Investigative Ophthalmology \& Visual Science, 48, 5052-5057. http://dx.doi.org/10.1167/iovs.07-0290

[40] Hess, L.M., Raebel, M.A., Conner, D.A., et al. (2006) Measurement of Adherence in Pharmacy Administrative Databases: A Proposal for Standard Definitions and Preferred Measures. Annals of Pharmacotherapy, 40, 1280-1288. http://dx.doi.org/10.1345/aph.1H018

[41] Santoleri, F., Sorice, P., Lasala, R., et al. (2013) Patient Adherence and Persistence with Imatinib, Nilotinib, Dasatinib in Clinical Practice. PLoS One, 8, e56813. http://dx.doi.org/10.1371/journal.pone.0056813

[42] Sattler, E.L., Lee, J.S. and Perri 3rd, M. (2013) Medication (Re)fill Adherence Measures Derived from Pharmacy Claims Data in Older Americans: A Review of the Literature. Drugs \& Aging, 30, 383-399. http://dx.doi.org/10.1007/s40266-013-0074-z

[43] Peterson, A.M., Nau, D.P., Cramer, J.A., et al. (2007) A Checklist for Medication Compliance and Persistence Studies Using Retrospective Database. Value in Health, 10, 3-12.

[44] WHO (2013) Guidelines for ATC Classification and DDD Assignment 2012. Collaborating Centre for Drug Statistics Methodology, Oslo. 